\title{
A Case of a Bleeding Duodenal Lipoma Successfully Controlled by Endoscopic Resection
}

\author{
Seo Yeon Gwak ${ }^{1}$, Mi Kyung Lee ${ }^{2}$ and Yong Kang Lee ${ }^{3}$ \\ ${ }^{1}$ Department of Internal Medicine, Yonsei University College of Medicine, Seoul, ${ }^{2}$ Department of Pathology, National Health Insurance \\ Service Ilsan Hospital, Goyang, ${ }^{3}$ Department of Internal Medicine and Institute of Gastroenterology, National Health Insurance Service Ilsan \\ Hospital, Goyang, Korea
}

This is a case report of successful endoscopic resection (ER) of a bleeding duodenal lipoma. An 85-year-old woman who was diagnosed with asymptomatic subepithelial tumor of the duodenum 3 years ago visited the emergency room with hematemesis and was admitted to our hospital. Emergent esophagogastroduodenoscopy revealed bleeding from an ulcer on the superior aspect of a subepithelial tumor measuring about $20 \mathrm{~mm}$ in diameter, at the superior duodenal angle. The ulcer was in the active stage (A1), with a visible vessel. The bleeding was controlled by ER of the tumor using a snare. The final pathological diagnosis was duodenal lipoma with mucosal ulceration. The patient showed no signs of bleeding for 10 days after the procedure; subsequently, she was discharged and followed up for regular checkups. Clin Endosc 2020;53:236-240

Key Words: Bleeding; Endoscopic resection; Lipoma of duodenum

\section{INTRODUCTION}

Gastrointestinal (GI) lipomas are uncommon and account for $4 \%$ of all benign GI tract tumors. The colon is the most common site of occurrence of lipomas. Duodenal lipomas are rare; only about $4 \%$ of lipomas occur in the duodenum, and the second portion of the duodenum is the most commonly affected site. ${ }^{1,2}$ Duodenal lipomas are rarely accompanied by symptoms, and when symptoms occur, they may include intussusception in younger patients, obstructive jaundice, or bleeding. ${ }^{3}$

Although lipomas are seldom considered the cause of GI bleeding, mucosal erosion or ulceration over a lipoma can

Received: January 23, 2019 Revised: May 29, 2019

Accepted: May 29, 2019

Correspondence: Yong Kang Lee

Department of Internal Medicine and Institute of Gastroenterology, National Health Insurance Service Ilsan Hospital, 100 Ilsan-ro, Ilsan-donggu, Goyang 10444, Korea

Tel: +82-31-900-3508, Fax: +82-31-900-6967, E-mail: lycky82@nhimc.or.kr ORCID: https://orcid.org/0000-0003-2929-4447

(cc) This is an Open Access article distributed under the terms of the Creative Commons Attribution Non-Commercial License (http://creativecommons.org/ licenses/by-nc/3.0) which permits unrestricted non-commercial use, distribution, and reproduction in any medium, provided the original work is properly cited. lead to severe bleeding. Bleeding does not typically occur in case of duodenal lipomas, and only a few cases of duodenal lipomas with bleeding have been reported worldwide. Herein, we report a case of duodenal lipoma with recurrent GI bleeding that was successfully treated by endoscopic resection (ER).

\section{CASE REPORT}

An 85-year-old woman presented to the emergency room with hematemesis, nausea, and vomiting for a few hours. She had a history of hypertension, diabetes mellitus, and end-stage renal disease (ESRD) and was on hemodialysis. She had been diagnosed with stable angina with coronary artery occlusive disease 3 months ago and was taking aspirin following the placement of a drug-eluting stent in the mid-left anterior descending artery. She had visited an outpatient clinic prior to her emergency room visit with a complaint of dizziness, and her hemoglobin level was declining. To identify the bleeding focus, esophagogastroduodenoscopy (EGD), colonoscopy, capsule endoscopy, abdominopelvic computed tomography (CT), and ${ }^{99 \mathrm{~m}}$ Technetium-labeled red blood cell scintigraphy were performed. Except for the duodenal lipoma, no other 
evidence of GI tract bleeding was observed (Fig. 1).

No signs of hemodynamic instability were observed during the emergency room visit. The vital signs of the patient were as follows: blood pressure of $155 / 57 \mathrm{mmHg}$, pulse rate of 84 $\mathrm{bpm}$, and body temperature of $36.1^{\circ} \mathrm{C}$. Physical examination revealed epigastric tenderness, and nasogastric tube irrigation results suggested active bleeding. Laboratory results were as follows: hemoglobin level of $4.6 \mathrm{~g} / \mathrm{dL}$, blood urea nitrogen (BUN) of $73.5 \mathrm{mg} / \mathrm{dL}$ (baseline BUN $<50 \mathrm{mg} / \mathrm{dL}$ ), and creatinine of $5.95 \mathrm{mg} / \mathrm{dL}$. The initial Glasgow-Blatchford bleeding score was 13 .

Emergent EGD was attempted for hemostasis, which revealed that an ulcer on the subepithelial tumor (SET) on the duodenum was the bleeding focus. The tumor, measuring 20 $\mathrm{mm}$ in diameter, was located at the superior duodenal angle, and the mucosal ulcer on it was in the active stage (A1), with a visible vessel on the surface (Forrest Type IIA). Initially, we failed to achieve complete control of the bleeding using hemoclips or electrical coagulation forceps, as we were unable to reach the bleeding site with the hemostatic devices. Endoscopic accessibility was limited because the ulcer was in the distal part of the tumor. The base of the ulcer became visible only after the SET was rotated using an endoscopic cap (Fig. 2). Partial hemostasis was achieved by an epinephrine injection.

Owing to subsequent events of massive hematemesis and hematochezia, the patient was moved to the intensive care unit for close monitoring of vital signs. A second EGD was performed, and we decided to remove the SET, as we found
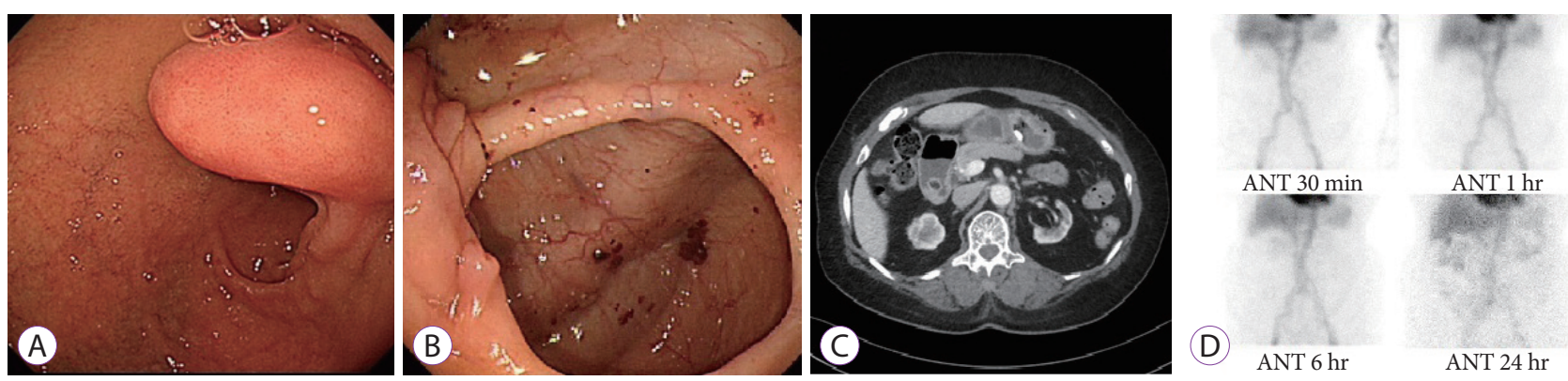

Fig. 1. Esophagogastroduodenoscopy and colonoscopy showing no peptic ulcers or evidence of gastrointestinal bleeding except for a duodenal subepithelial tumor (A, B) computed tomography scan showing a hypoattenuating lesion about $1.7 \mathrm{~cm}$ in diameter in the duodenum, suspected to be a lipoma (C) a ${ }^{99 \mathrm{~m}} \mathrm{Technetium-labeled}$ red blood cell scintigraphy showing no abnormal uptake for 24 hours (D). ANT, anterior.
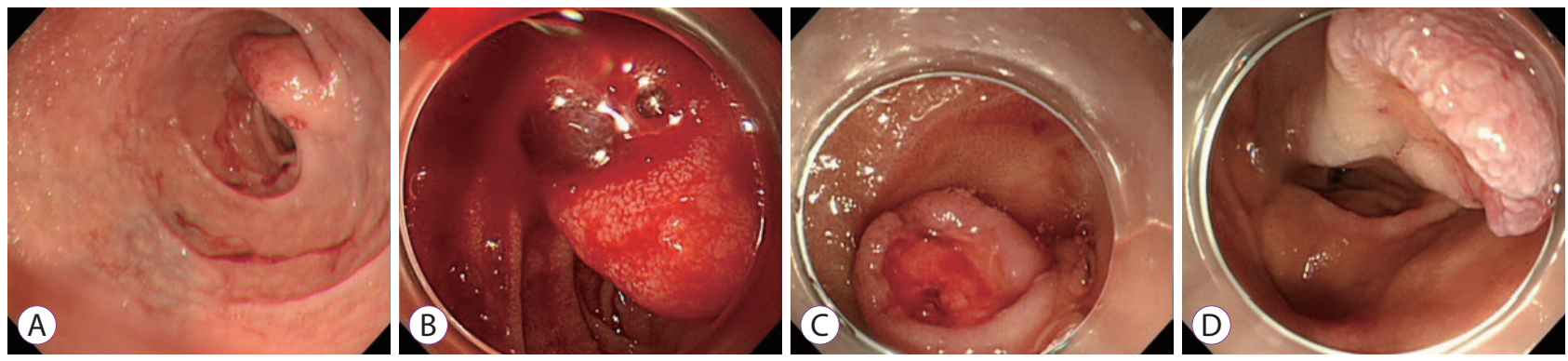

Fig. 2. Emergent esophagogastroduodenoscopy showing a subepithelial tumor (SET) at the duodenal bulb with a small blood clot (A) an oozing pattern of active bleeding observed after rotating the SET (B) bleeding arrested after injection of epinephrine into the lesion (C, D).
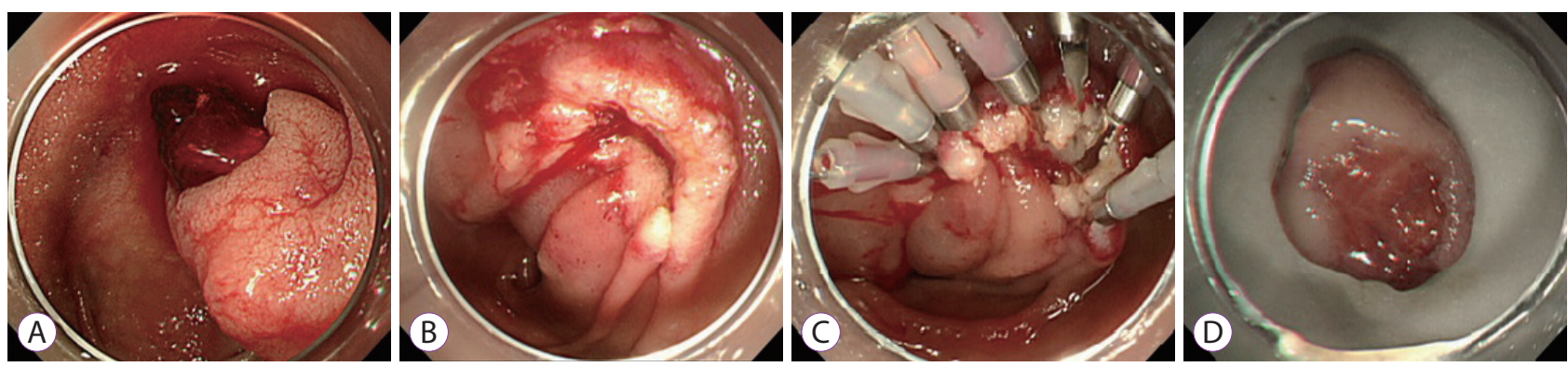

Fig. 3. A second esophagogastroduodenoscopy is performed after a later bleeding event. Blood clots observed on the surface of the ulcer on subepithelial tumor (A) polypectomy using a snare and the mucosal defect closed using hemoclips $(B, C)$ the resected specimen is about $20 \mathrm{~mm}$ in diameter (D). 
blood clots at the base of the ulcer. Initially, we considered using a detachable snare. However, as the tumor was located opposite the endoscopic channel, it was difficult to reach the tumor with a detachable snare. Moreover, since the lipoma

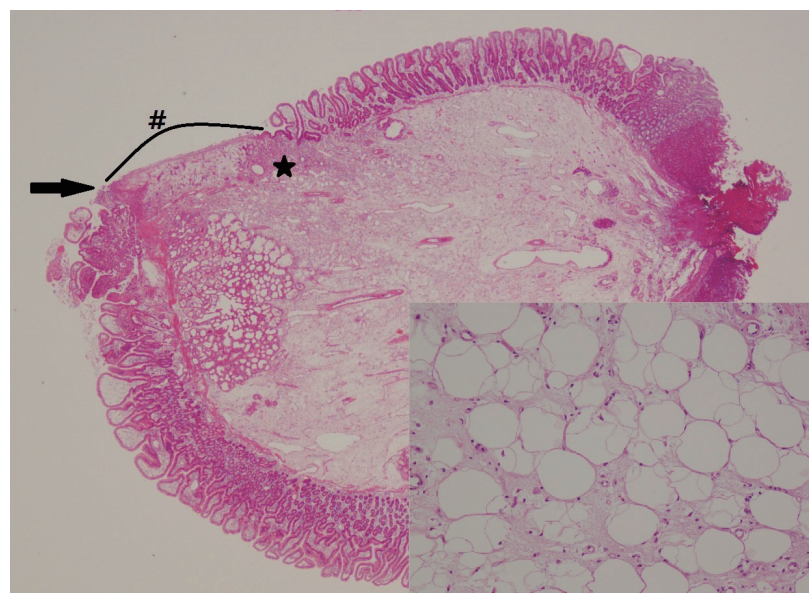

Fig. 4. A submucosal lipoma with mucosal ulceration (\#), hemorrhage (black arrow), and granulation tissue $\left(^{*}\right)$ (hematoxylin and eosin [H\&E], $\times 10$ ); high-power view showing mature adipose tissue $(H \& E, \times 200)$. was unpedunculated with an obtuse neck, a broad base, and was too slippery to grasp, a detachable snare could not be used. Finally, the tumor was successfully removed by ER using a snare, and the mucosal defect was closed using hemoclips (HX-5LR-1 with standard clip; Olympus, Tokyo, Japan) despite concerns over possible perforation and rebleeding (Fig. 3). Reduction and subsequent arrest of bleeding was observed after the procedure; the patient resumed diet after 3 days and was discharged 1 week later.

Pathological examination revealed a polypoid mass, measuring $2 \times 1.5 \times 1.3 \mathrm{~cm}$, covered with congested duodenal mucosa and some ulcerations. Microscopically, the tumor consisted of mature adipose tissue in the submucosa, which is consistent with a diagnosis of submucosal lipoma. There was an area of mucosal ulceration covered with fibrinous exudate with zones of hemorrhage and healing (superficial granulation tissue) (Fig. 4).

\section{DISCUSSION}

Fewer than 30 cases of duodenal lipomas with active GI

Table 1. Case Reports of Duodenal Lipomas Present with Upper Gastrointestinal Bleeding

\begin{tabular}{|c|c|c|c|c|c|c|c|c|}
\hline Study & Age & Sex & Symptoms & Location & $\begin{array}{l}\text { Size } \\
(\mathrm{mm})\end{array}$ & & Endoscopic findings & Treatment \\
\hline Tung et al. $(2001)^{11}$ & 73 & M & Melena & D2 & 45 & Ip & Active oozing of blood & Polypectomy \\
\hline Park et al. $(2005)^{12}$ & 24 & M & Melena & D2 & 30 & Ip & Red spot on the surface tip & $\begin{array}{l}\text { Polypectomy } \\
\text { and transduodenal resection }\end{array}$ \\
\hline Sou et al. $(2006)^{6}$ & 81 & $\mathrm{~F}$ & Melena & D3 & 50 & Ip & $\begin{array}{l}\text { Small ulcers had formed in } \\
\text { part, exposing vessels }\end{array}$ & Polypectomy \\
\hline Kim et al. $(2006)^{5}$ & 62 & $\mathrm{~F}$ & Melena & D2 & 30 & Ip & $\begin{array}{l}\text { Small ulcers had formed in } \\
\text { part, exposing vessels }\end{array}$ & $\begin{array}{l}\text { Polypectomy } \\
\text { with detachable snare }\end{array}$ \\
\hline $\begin{array}{l}\text { Mohamed et al. } \\
(2008)^{7}\end{array}$ & 70 & $\mathrm{~F}$ & GI bleeding & $\mathrm{D} 2$ & 55 & N/A & $\mathrm{N} / \mathrm{A}$ & Polypectomy \\
\hline $\begin{array}{l}\text { Ouwerkerk et al. } \\
(2010)^{13}\end{array}$ & 52 & $\mathrm{~F}$ & GI bleeding & D1 & 17 & Ip & $\begin{array}{l}\text { Small ulcers had formed in } \\
\text { part, exposing vessels }\end{array}$ & Transduodenal resection \\
\hline $\begin{array}{l}\text { Chang et al. } \\
(2010)^{14}\end{array}$ & 59 & $\mathrm{~F}$ & Melena & $\mathrm{D} 2$ & 40 & Ip & $\begin{array}{l}\text { Small ulcers had formed in } \\
\text { part, exposing vessels }\end{array}$ & Transduodenal resection \\
\hline $\begin{array}{l}\text { Kadaba et al. } \\
(2011)^{15}\end{array}$ & 60 & $\mathrm{~F}$ & $\begin{array}{l}\text { None } \\
\text { IDA work up }\end{array}$ & D1 & 60 & Ip & $\begin{array}{l}\text { ulcerated surface and a } \\
\text { broad base }\end{array}$ & Transduodenal resection \\
\hline Efe et al. $(2012)^{8}$ & 76 & M & GI bleeding & D2 & 40 & N/A & $\mathrm{N} / \mathrm{A}$ & $\begin{array}{l}\text { Polypectomy } \\
\text { with detachable snare }\end{array}$ \\
\hline $\begin{array}{l}\text { Thorlacius et al. } \\
(2013)^{9}\end{array}$ & 66 & M & Melena & $\mathrm{D} 2$ & 35 & Ip & $\begin{array}{l}\text { Small ulcers had formed in } \\
\text { part, exposing vessels }\end{array}$ & Polypectomy \\
\hline $\begin{array}{l}\text { Yaman et al. } \\
(2014)^{10}\end{array}$ & 59 & $\mathrm{~F}$ & $\begin{array}{c}\text { None } \\
\text { FOBT }(+)\end{array}$ & D2 & 40 & N/A & N/A & Polypectomy \\
\hline Present case & 85 & $\mathrm{~F}$ & Hematemesis & D1 & 20 & Ip & $\begin{array}{l}\text { Small ulcers had formed in } \\
\text { part, exposing vessels }\end{array}$ & Polypectomy \\
\hline
\end{tabular}

FOBT, fecal occult blood test; GI, gastrointestinal; IDA, iron deficiency anemia; N/A, not available. 
bleeding have been reported. ${ }^{4}$ Moreover, only a few reports of successful ER of duodenal lipomas with bleeding have been published. ${ }^{5-11}$

We summarized a review of the literature on duodenal lipomas with GI bleeding (Table 1) ${ }^{5-15}$ We conducted an online search in PubMed for "duodenal lipoma" and "bleeding". The etiology of the ulceration and bleeding in the lipomas was unclear, the overlying mucosae of most duodenal lipomas were intact, and some duodenal lipomas had mucosae with areas of ulceration or erosion. Recent reports suggest that the ulceration may be associated with mucosal pressure atrophy or peristalsis leading to elongation, stretching, and necrosis of the overlying mucosa. ${ }^{3}$

To the best of our knowledge, this is the second report of successful ER of duodenal lipoma with bleeding in Korea. Only two cases of ER of duodenal lipoma with bleeding in Korea have been reported. The first case, reported by Park et al. in 2005, was of a patient who underwent surgery for massive bleeding 2 days after polypectomy. ${ }^{12}$ In the other case, reported by Kim et al. in 2006, a detachable snare was used and hemostasis was successful; but unlike the present case, endoloops were used in the latter case. ${ }^{5}$

The lipomas in the two previously reported cases were located in the second portion of the duodenum, and it was relatively easy to identify the ulcers on the superior aspect of the SETs. Our case differs from those in earlier reports in that the lipoma in our case was found at the superior duodenal angle; moreover, we resected the tumor using a snare, and not endoloops, and closed the mucosal defect with hemoclips.

In general, asymptomatic duodenal SETs including lipomas may only be observed, but symptomatic duodenal lipomas should be removed even if the symptoms are not severe. CT scans can be fairly accurate, and they facilitate the pretreatment diagnosis of lipomas. Lipomas are homogeneous tumors with well-defined borders, uniform fat attenuation of 70-120 Hounsfield units on CT, and may contain a few thin internal septations. Magnetic resonance imaging is also reliable for diagnosing GI-system lipomas, which have short $\mathrm{T} 1$ and relatively long $\mathrm{T} 2$ relaxation times and, therefore, appear hyperintense on T1-weighted images and intermediately intense to hyperintense on T2-weighted fast spin-echo and gradient-echo images relative to muscle. ${ }^{16}$ Although CT is useful for diagnosis, it does not accurately identify the bleeding focus and the origin of the lesion because of the polypoid nature of lipomas. Endoscopic ultrasound (EUS) features of a homogenous hyperechoic mass in the submucosal layer are highly specific to duodenal lipomas, and EUS can also visualize the depth of invasion. ${ }^{17}$

Although symptomatic duodenal SETs can typically be removed by surgical treatment or ER, there is no consensus on the treatment options. ${ }^{18}$ ER with wound closure using clips and an endoloop is an effective and reasonably safe method for the treatment and removal of duodenal tumors, ${ }^{11}$ and it can be an alternative option for treatment of patients with duodenal lipomas. ER of duodenal lesions is still considered a challenging procedure, with potentially serious complications including perforation and delayed bleeding. ${ }^{19}$

In the current case, the ulcer on the surface of the duodenal lipoma was found to be the bleeding focus, and it may be the same lesion that caused the GI bleeding for which our patient had visited the outpatient clinic earlier. Unfortunately, the ulcer was not discovered earlier because it was difficult to determine its location, which was the distal part of the tumor. This case report suggests that it is important that endoscopists determine whether an SET is the bleeding focus when a patient presents with signs of recurrent GI bleeding. Moreover, in cases such as ours, patients are likely to be under the influence of factors that may increase bleeding tendency. In our case, the patient was on hemodialysis because of ESRD, which could induce platelet dysfunction, and the hemodialysis process itself may have contributed to the bleeding. Further, she was on aspirin, which could not be discontinued, because she was fitted with a drug-eluting stent for coronary artery occlusive disease not more than 4 months ago.

In conclusion, our case suggests that meticulous inspection of duodenal SETs is necessary in patients suspected of having bleeding foci, and ER may be a suitable treatment option for symptomatic duodenal lipomas.

\section{Conflicts of Interest}

The authors have no financial conflicts of interest.

\section{REFERENCES}

1. O’Riordan BG, Vilor M, Herrera L. Small bowel tumors: an overview. Dig Dis 1996;14:245-257.

2. Wilson JM, Melvin DB, Gray G, Thorbjarnarson B. Benign small bowel tumor. Ann Surg 1975;181:247-250.

3. Pei MW, Hu MR, Chen WB, Qin C. Diagnosis and treatment of duodenal lipoma: a systematic review and a case report. J Clin Diagn Res 2017;11:PE01-PE05.

4. Ye LP, Mao XL, Zheng HH, et al. Safety of endoscopic resection for duodenal subepithelial lesions with wound closure using clips and an endoloop: an analysis of 68 cases. Surg Endosc 2017;31:1070-1077.

5. Kim GM, Chung WC, Hwang SS, et al. Endoscopic removal of bleeding duodenal lipoma using a detachable snare. Korean J Gastrointest Endosc 2006;33:100-104.

6. Sou S, Nomura H, Takaki Y, et al. Hemorrhagic duodenal lipoma managed by endoscopic resection. J Gastroenterol Hepatol 2006;21:479-481.

7. Mohamed HK, Suresh CC, Alexander KG, Neena M. Bleeding duodenal lipoma treated with endoscopic polypectomy. Trop Gastroenterol 2008;29:167-168.

8. Efe C, Purnak T, Ozaslan E, Kücükciloglu Y. Which is the best approach for the hemorrhagic duodenal lipoma: endoscopic resection or surgery? 
Am J Surg 2012;203:558.

9. Thorlacius H, Weiber H, Ljungberg O, Nielsen J, Toth E. Endoscopic diagnosis and treatment of a giant duodenal lipoma presenting with gastrointestinal bleeding. Endoscopy 2013;45(Suppl 2):E385-E386.

10. Yaman I, Derici H, Paksoy S. Symptomatic duodenal lipoma with endoscopic snare polypectomy. Ulus Cerrahi Derg 2014;30:103-105.

11. Tung CF, Chow WK, Peng YC, Chen GH, Yang DY, Kwan PC. Bleeding duodenal lipoma successfully treated with endoscopic polypectomy. Gastrointest Endosc 2001;54:116-117.

12. Park JB, Park SW, Yang YS, et al. A case of duodenal lipoma with upper gastrointesinal bleeding. Korean J Gastrointest Endosc 2005;31:126-129.

13. Ouwerkerk HM, Raber, Freling G, Klaase JM. Duodenal lipoma as a rare cause of upper gastrointestinal bleeding. Gastroenterology Res 2010;3:290-292.

14. Chang CW, Chu CH, Shih SC, Chen MJ, Yang TL, Chang WH. Duodenal polypoid lipoma with bleeding. Am J Surg 2010;200:e49-e50
15. Kadaba R, Bowers KA, Wijesuriya N, Preston SL, Bray GB, Kocher HM. An unusual cause of gastrointestinal bleeding: duodenal lipoma. Case Rep Gastroenterol 2011;5:183-188.

16. Genchellac H, Demir MK, Ozdemir H, Unlu E, Temizoz O. Computed tomographic and magnetic resonance imaging findings of asymptomatic intra-abdominal gastrointestinal system lipomas. J Comput Assist Tomogr 2008;32:841-847.

17. Nakamura S, Iida M, Suekane H, Matsui T, Yao T, Fujishima M. Endoscopic removal of gastric lipoma: diagnostic value of endoscopic ultrasonography. Am J Gastroenterol 1991;86:619-621.

18. Kim TW, Kim GH, Park DY, et al. Endoscopic resection for duodenal subepithelial tumors: a single-center experience. Surg Endosc 2017;31:1936-1946

19. Fujihara S, Mori H, Kobara H, et al. Management of a large mucosal defect after duodenal endoscopic resection. World J Gastroenterol 2016;22:6595-6609 